\section{RSP}

http://www.rsp.fsp.usp.br/
Revista de Saúde Pública

\title{
Sociocultural factors related to the physical activity in boys and girls: PeNSE 2012
}

\author{
Luciano Antonacci Condessa',"1 (iD), Otaviana Cardoso Chaves" (iD, Fernanda Marcelina Silva"'I (iD),

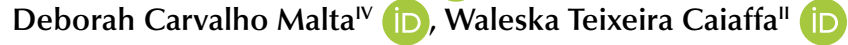 \\ ' Instituto Federal Fluminense de Educação, Ciência e Tecnologia. Itaperuna, RJ, Brasil \\ " Universidade Federal de Minas Gerais. Faculdade de Medicina. Observatório de Saúde Urbana de Belo \\ Horizonte. Belo Horizonte, MG, Brasil \\ III Universidade Federal de Minas Gerais. Programa de Pós-Graduação em Ciências Aplicadas à Saúde do Adulto. \\ Belo Horizonte, MG, Brasil \\ iv Universidade Federal de Minas Gerais. Escola de Enfermagem. Departamento de Enfermagem Materno Infantil \\ e Saúde Pública. Belo Horizonte, MG, Brasil
}

\author{
Correspondence: \\ Luciano Antonacci Condessa \\ Faculdade de Medicina/ \\ Observatório de Saúde Urbana - \\ OSUBH/UFMG \\ Av. Professor Alfredo Balena, 190 \\ $7^{\circ}$ andar sala 730 Santa Efigênia \\ 30130-100 Belo Horizonte, MG, \\ Brasil \\ E-mail: lucianoantonacci@yahoo. \\ com.br
}

Received: Oct 11, 2017

Approved: Apr 10, 2018

How to cite: Condessa LA, Chaves OC, Silva FM, Malta DC, Caiaffa WT. Sociocultural factors related to the physical activity in boys and girls: PeNSE 2012. Rev Saude Publica. 2019;53:25.

Copyright: This is an open-access article distributed under the terms of the Creative Commons Attribution License, which permits unrestricted use, distribution, and reproduction in any medium, provided that the original author and source are credited.

\section{ABSTRACT}

OBJECTIVE: To verify in male and female Brazilian adolescents the association of demographic, psychosocial, behavioral and sociocultural characteristics with the regular practice of physical activity.

METHODS: The sample consisted of 109,104 adolescents from all Brazilian states attending the 9 th year of elementary education in 2012. The response variable was the regular practice of physical activity (300+ minutes/week). The explanatory variables were grouped into four fields: demographic, psychosocial, behavioral and sociocultural. The Poisson regression was stratified by sex to evaluate the association.

RESULTS: The prevalence of active adolescents was $20.2 \%$, higher in boys $(27.9 \%)$ than in girls (13.1\%). It was observed a greater practice of physical activity in boys of lower age group, children of mothers with higher schooling, who consumed healthy foods such as beans, fruits, vegetables, and milk, as well as among those with family supervision. At the same time, unhealthy habits such as insomnia and alcohol consumption were also positively associated with physical activity. In girls, greater physical activity was observed among those who lived with mothers and whose mothers had higher schooling. In addition to family supervision, the practice of physical activity in girls was also positively associated with the frequency of meals with their parents. However, as in boys, insomnia and alcohol consumption were associated with an increase in the practice of physical activity.

CONCLUSIONS: One-fifth of adolescents practice physical activity regularly, demonstrating the need for specific public policies to increase the percentage of active young people in the country. Maternal schooling, healthy eating habits and family supervision were associated with regular physical activity in boys and girls, evidencing the importance of the family for the acquisition of healthy habits in this age group.

DESCRIPTORS: Adolescent. Sports. Exercise. Socioeconomic Factors. Health Surveys. 


\section{INTRODUCTION}

The regular practice of physical activity (PA) in adolescents, defined as 60 minutes per day PA with moderate to vigorous intensity, is associated with a number of health benefits, such as increased cardiorespiratory capacity, muscular strength and bone density, as well as reduction of obesity, levels of lipoprotein and depression ${ }^{1}$.

Assessing the percentage of active young people in several countries, it is verified that only $19.5 \%$ of adolescents practice PA regularly². In Brazil, the Pesquisa Nacional de Saúde Escolar (National School Health Survey - PeNSE), conducted with 102,072 adolescents, found that $20.3 \%$ of them are active ${ }^{3}$. These results are worrying, since the habits acquired by these young people tend to remain in adult life ${ }^{3-5}$.

Some studies, especially those using an ecological model, show that increasing of PA practice is a complex process determined by a relation of individual factors (biological and psychological), interpersonal (family social support and cultural norms) and environmental (violence and climate), besides aspects related to national policy (urban planning and parks construction) and global (economic development) ${ }^{6}$. These factors have been grouped according to their characteristics in the demographic fields (sex and skin color), psychosocial (self-efficacy and stress), behavioral (smoking and eating habits), sociocultural (family support for PA) and environmental (proximity to parks) ${ }^{6}$.

Certain demographic characteristics of the adolescent, such as being male, with a lower age group and a mother with a higher educational level, are already well established in the literature and associated with regular practice of $\mathrm{PA}^{5,7,8}$. A study demonstrates that family composition interferes in the level of PA of adolescents, but differently in boys and girls 9 . The importance of health-related behaviors in the practice of PA is also highlighted. Fernandes et al. ${ }^{10}$ revealed that the increase in PA is associated with healthy eating habits while Bedendo and Noto $^{11}$ reported an increase in alcohol consumption associated with this practice.

Since these associations may vary among boys and girls, and there are few researches investigating associations of these and other factors with PA in representative samples from all over Brazil, this study aimed to verify the association of demographic, psychosocial, behavioral and sociocultural characteristics with the regular practice of PA in Brazilian male and female adolescents. Understanding these relationships may contribute to the development of intervention programs that aims increasing the prevalence of active youth.

\section{METHODS}

This is a cross-sectional study, with information from the second edition of PeNSE, conducted with 109,104 adolescents in 2012 . PeNSE 2012 is a partnership between the Ministry of Health and the Brazilian Institute of Geography and Statistics, with the support of the Ministry of Education, and aimed to investigate risk factors and health protection of adolescents. The students from ninth year of elementary education, mostly aged between 13 and 15 years, from public or private schools located in urban or rural areas of a set of Brazilian municipalities were the target population of the research. The selection of the sample was made based on the register of schools ranked by the 2010 School Census, conducted by the National Institute of Studies and Educational Research Anísio Teixeira, Ministry of Education, excluding schools with fewer than 15 students in that school year ${ }^{4}$.

Sample design was structured to estimate proportions or prevalence in the following geographic fields: 26 Brazilian capitals and the Federal District, all these capitals, five regions of the country (North, Northeast, Southeast, South and Midwest) and Brazil as a whole. Further details on sample design are available at PeNSE $2012^{4}$.

PeNSE 2012 data collection was performed using a smartphone containing a structured and self-administered questionnaire divided into modules by subject: sociodemographic 
characteristics; job; food; body image; PA; consumption of tobacco, alcohol and other drugs; safety nets; hygiene habits; mental health; oral health; asthma; sexual behavior; violence; accidents; and use of health services ${ }^{4}$.

\section{Description of Variables}

In this study, the response variable was the regular practice of PA, measured by the globally estimated physical activity indicator, using the question: "How many days did you have PA for at least 60 minutes (one hour) on the last seven days?”. Adolescents who did at least 60 minutes of PA in five days or more were considered active. This variable was categorized as insufficiently active ( $<300 \mathrm{~min} /$ week$)$ and active $(\geq 300 \mathrm{~min} / \text { week })^{4,8,9}$.

Explanatory variables included in the study were grouped, by affinity, into four fields ${ }^{6}$. In the demographic field, the following variables were evaluated: age group ( $\leq 13 ; 14 ; 15 ; \geq 16$ years), skin color (white; black; yellow; brown; indigenous) ${ }^{8}$, kind of school (private; public) ${ }^{8}$, current adolescent work (yes; no) ${ }^{8}$, mother's schooling (without schooling; incomplete or complete elementary education; incomplete or complete secondary education; incomplete or complete higher education) ${ }^{12}$, living with parents (live with the mother and the father; only with the father; only with the mother; do not live with father or mother) ${ }^{9}$.

In the psychosocial field, the following variables were evaluated: feeling of loneliness ${ }^{4}$ (never, rarely, sometimes; often, always), report of insomnia (never, rarely, sometimes; often, always) ${ }^{4}$ and the existence of close friends (no, one friend or more) ${ }^{4}$.

The variables evaluated in the behavioral field were: regular consumption of healthy foods such as beans, fruits, vegetables and milk (five times or more in the week) ${ }^{4}$, regular use of tobacco and alcohol in the last 30 days (never; none day; one or more days) ${ }^{4}$ and if they ever tried drugs (no; yes) $)^{4}$.

In the sociocultural field, were evaluated: frequency of meals in the presence of the mother, father or guardian (four or fewer meals per week or five meals or more per week) ${ }^{4}$; family supervision, defined as the knowledge of guardians about what the adolescent does in free time (never, rarely, sometimes or often/always) ${ }^{4}$; report of domestic physical aggression with the adolescent as the victim (not once in the last 30 days or once or more in the last 30 days) ${ }^{4}$; reaction of parents or guardians if the adolescent arrived drunk, according to the adolescent (they would care a little, they would not care, do not know, they would care a lot) ${ }^{4}$; absences at school without parental or guardian permission (none day in the last 30 days or one to ten days in the last 30 days $)^{4}$.

Additionally, the socioeconomic status was analyzed through a score of goods and services, categorized in tertiles. In this approach, we considered the goods and services with a lower prevalence than $70 \%$ (landline, computer, internet access, car, motorcycle, shower, maid). Weights were assigned to the presence of each of them, corresponding to the complement of the relative frequency in the sample studied. Thus, the items that were less frequent received a greater weight ${ }^{13}$.

\section{Data Analysis}

First, a descriptive analysis was performed, presenting the proportions of the variables according to the adolescents' PA, stratified by sex. Bivariate Poisson regression was performed to verify the factors associated with PA, with estimates of the prevalence ratio (PR) and their respective trust intervals $(95 \% \mathrm{CI})$. The variables that presented $\mathrm{p}<0.20$ in the bivariate were included in the multivariate model; the only variable included even without this criterion was the regular use of tobacco in both sexes, due to its epidemiological relevance. In the final model the variables with $\mathrm{p} \leq 0.05$ remained.

The suitability of the models was verified by goodness-of-fit. Analyzes were done in Stata software version 12.0 (Stata Corporation, College Station, USA), considering the complexity 
of the sample design. In addition, the goods and services score was used to assess if the sample loss of the mother's educational variable was differential or not.

\section{Ethical Aspects}

PeNSE 2012 was approved by the National Commission for Research Ethics under registry number 16805. The conduct of the research is in accordance with the Declaration of Helsinki, with the voluntary participation of the adolescents and all information, both student and school, confidential and unidentified.

\section{RESULTS}

Table 1 presents the descriptive analysis of the explanatory variables used in this study. PeNSE 2012 evaluated 109,104 adolescents, most of them female (52.2\%), aged 14 years old (45.5\%) and public school student (82.8\%). Regular PA practice was observed in 20.2\% (95\%CI 19.6-20.7) of adolescents, being more prevalent in boys $(27.9 \%$, 95\% CI $27.0-28.8)$ than girls (13.1\%, 95\%CI 12.6-13.6), with $\mathrm{p} \leq 0.05$.

Table 1. Demographic, psychosocial, behavioral and sociocultural characteristics of Brazilian adolescents.

\begin{tabular}{|c|c|c|c|c|c|c|}
\hline \multirow{2}{*}{ Variable } & \multicolumn{2}{|c|}{ Total } & \multicolumn{2}{|c|}{ Male } & \multicolumn{2}{|c|}{ Female } \\
\hline & $\%$ & $95 \% \mathrm{Cl}$ & $\%$ & $95 \% \mathrm{Cl}$ & $\%$ & $95 \% \mathrm{Cl}$ \\
\hline \multicolumn{7}{|l|}{ Age group (years old) } \\
\hline$\leq 13$ & 22.9 & $17.0-28.8$ & 19.8 & $13.8-25.8$ & 25.8 & $19.8-31.8$ \\
\hline 14 & 45.5 & $42.4-48.7$ & 43.9 & $39.9-47.9$ & 47.1 & $44.4-49.7$ \\
\hline 15 & 18.4 & $14.4-22.3$ & 20.5 & $16.7-24.3$ & 16.4 & $12.2-20.6$ \\
\hline$\geq 16$ & 13.2 & $8.4-18.0$ & 15.8 & $9.9-21.8$ & 10.8 & $6.7-14.8$ \\
\hline \multicolumn{7}{|l|}{ Skin color } \\
\hline White & 36.8 & $31.6-42.0$ & 38.7 & $33.3-44.1$ & 35.0 & $30.1-40.0$ \\
\hline Black & 13.4 & $11.1-15.6$ & 15.5 & $13.0-18.0$ & 11.4 & $9.2-13.5$ \\
\hline Yelow & 4.1 & $3.4-4.8$ & 3.8 & $3.4-4.1$ & 4.4 & $3.3-5.6$ \\
\hline Brown & 42.2 & $39.1-45.4$ & 38.5 & $35.3-41.6$ & 45.7 & $42.6-48.8$ \\
\hline Indigenous & 3.5 & $2.8-4.3$ & 3.6 & $2.7-4.5$ & 3.5 & $2.8-4.2$ \\
\hline \multicolumn{7}{|l|}{ Kind of school } \\
\hline Public & 82.8 & $78.2-87.4$ & 82.3 & $76.9-87.7$ & 83.3 & $79.4-87.3$ \\
\hline Private & 17.2 & $12.6-21.8$ & 17.7 & $12.3-23.1$ & 16.7 & $12.7-20.6$ \\
\hline \multicolumn{7}{|l|}{ Work currently } \\
\hline Yes & 13.1 & $12.2-14.1$ & 17.4 & $16.1-18.8$ & 9.2 & $8.4-10.0$ \\
\hline No & 86.9 & $85.9-87.8$ & 82.6 & $81.2-83.9$ & 90.8 & $90.0-91.6$ \\
\hline \multicolumn{7}{|l|}{ Mother's schooling } \\
\hline Without schooling & 10.1 & $8.3-11.9$ & 9.7 & $8.4-10.9$ & 10.4 & $8.1-12.8$ \\
\hline Elementary education (incomplete/complete) & 41.8 & $39.9-43.8$ & 40.3 & $37.9-42.7$ & 43.2 & $41.1-45.3$ \\
\hline Secondary education (incomplete/complete) & 31.8 & $28.3-35.4$ & 32.2 & $28.5-35.9$ & 31.5 & $27.8-35.2$ \\
\hline Higher education (incomplete/complete) & 16.3 & $14.7-17.8$ & 17.8 & $16.4-19.2$ & 14.8 & $13.3-16.4$ \\
\hline \multicolumn{7}{|l|}{ Living with parents } \\
\hline Do not live with parents & 5.4 & $5.0-5.8$ & 4.6 & $4.1-5.1$ & 6.1 & $5.7-6.5$ \\
\hline Only father & 4.0 & $3.8-4.1$ & 4.8 & $4.6-5.0$ & 3.2 & $3.1-3.4$ \\
\hline Only Mother & 28.4 & $26.9-30.0$ & 26.5 & $25.2-27.8$ & 30.2 & $28.4-32.0$ \\
\hline Both & 62.2 & $60.2-64.2$ & 64.0 & $62.3-65.8$ & 60.5 & $58.3-62.7$ \\
\hline \multicolumn{7}{|l|}{ Feeling of loneliness } \\
\hline Yes & 16.5 & $16.1-16.8$ & 10.7 & $10.4-11.0$ & 21.7 & $21.2-22.2$ \\
\hline No & 83.6 & $83.2-83.9$ & 89.3 & $89.0-89.6$ & 78.3 & $77.8-78.8$ \\
\hline
\end{tabular}


Table 1. Demographic, psychosocial, behavioral and sociocultural characteristics of Brazilian adolescents. (Continuation)

\begin{tabular}{|c|c|c|c|c|c|c|}
\hline \multicolumn{7}{|l|}{ Insomnia } \\
\hline Yes & 9.7 & $9.3-10.1$ & 6.3 & $6.2-6.5$ & 12.8 & $12.1-13.5$ \\
\hline No & 90.3 & 89.9-90.7 & 93.7 & $93.5-93.8$ & 87.2 & $86.5-87.9$ \\
\hline \multicolumn{7}{|l|}{ Close friends } \\
\hline No & 3.5 & $3.3-3.7$ & 4.6 & $4.2-5.0$ & 2.5 & $2.4-2.6$ \\
\hline 1 friend or more & 96.5 & $96.3-96.7$ & 95.4 & $95.0-95.8$ & 97.5 & $97.4-97.6$ \\
\hline \multicolumn{7}{|c|}{ Regular consume of beans ( $\geq 5 x /$ week) } \\
\hline No & 30.1 & $27.4-32.8$ & 25.3 & $22.6-28.0$ & 34.4 & $31.3-37.5$ \\
\hline Yes & 69.9 & $67.2-72.6$ & 74.7 & $72.0-77.4$ & 65.6 & $62.5-68.7$ \\
\hline \multicolumn{7}{|c|}{ Regular consume of fruits ( $\geq 5 x /$ week) } \\
\hline No & 69.8 & $68.9-70.7$ & 70.4 & $69.8-71.1$ & 69.2 & $68.1-70.3$ \\
\hline Yes & 30.2 & $29.3-31.1$ & 29.6 & $28.9-30.2$ & 30.8 & $29.7-31.9$ \\
\hline \multicolumn{7}{|c|}{ Regular consume of vegetables ( $\geq 5 x /$ week) } \\
\hline No & 65.2 & $63.3-67.2$ & 66.2 & $64.4-67.9$ & 64.4 & $62.2-66.5$ \\
\hline Yes & 34.8 & $32.8-36.7$ & 33.8 & $32.1-35.6$ & 35.6 & $33.5-37.8$ \\
\hline \multicolumn{7}{|c|}{ Regular consume of milk ( $\geq 5 x /$ week) } \\
\hline No & 48.5 & $45.2-51.7$ & 45.3 & $41.7-49.0$ & 51.3 & $48.4-54.3$ \\
\hline Yes & 51.6 & $48.3-54.8$ & 54.7 & $51.0-58.3$ & 48.7 & $45.7-51.6$ \\
\hline \multicolumn{7}{|l|}{ Regular consume of tobacco } \\
\hline Yes & 5.1 & $3.9-6.2$ & 5.1 & $4.4-5.9$ & 5.0 & $3.5-6.6$ \\
\hline No & 94.9 & $93.8-96.1$ & 94.9 & $94.1-95.6$ & 95.0 & $93.4-96.5$ \\
\hline \multicolumn{7}{|l|}{ Regular consume of alcohol } \\
\hline Yes & 26.1 & $24.5-27.7$ & 25.2 & $23.0-27.5$ & 26.9 & $25.7-28.0$ \\
\hline No & 73.9 & $72.3-75.5$ & 74.8 & $72.5-77.0$ & 73.1 & $72.0-74.3$ \\
\hline \multicolumn{7}{|l|}{ Drugs trying } \\
\hline Yes & 7.1 & $5.0-9.1$ & 7.9 & $5.8-9.9$ & 6.3 & $4.3-8.3$ \\
\hline No & 92.9 & $90.9-95.0$ & 92.1 & $90.1-94.2$ & 93.7 & $91.7-95.7$ \\
\hline \multicolumn{7}{|c|}{ Frequency of meals with parents/guardian } \\
\hline 4 fewer meals per week & 33.6 & $31.6-35.6$ & 30.9 & $29.4-32.5$ & 36.0 & $33.5-38.6$ \\
\hline 5 meals or more per week & 66.4 & $64.4-68.4$ & 69.1 & $67.5-70.6$ & 64.0 & $61.4-66.5$ \\
\hline \multicolumn{7}{|l|}{ Family supervision } \\
\hline No & 41.6 & $41.0-42.1$ & 45.5 & $44.7-46.2$ & 37.9 & $37.3-38.6$ \\
\hline Yes & 58.5 & $57.9-59.0$ & 54.5 & $53.8-55.3$ & 62.1 & $61.4-62.7$ \\
\hline \multicolumn{7}{|c|}{ Victim of domestic physical aggression } \\
\hline Yes & 10.6 & $10.1-11.1$ & 9.6 & $8.2-11.0$ & 11.5 & $107-12.3$ \\
\hline No & 89.4 & $88.9-89.9$ & 90.4 & $89.0-91.8$ & 88.5 & $87.7-89.3$ \\
\hline \multicolumn{7}{|c|}{ Reaction of parents or guardians if the adolescent arrived drunk } \\
\hline They would care a little & 10.3 & $10.1-10.4$ & 11.3 & $11.0-11.6$ & 9.4 & $9.1-9.7$ \\
\hline They would care so much & 89.7 & 89.6-89.9 & 88.7 & $88.4-89.0$ & 90.6 & $90.3-90.9$ \\
\hline \multicolumn{7}{|c|}{ Absences at school without parental or guardian permission } \\
\hline Yes & 25.8 & $24.6-27.0$ & 28.0 & $26.5-29.4$ & 23.8 & $22.6-25.0$ \\
\hline No & 74.2 & $73.0-75.4$ & 72.0 & $70.6-73.5$ & 76.2 & $75.0-77.4$ \\
\hline
\end{tabular}

The mother's schooling was absent for $18.6 \%$ of adolescents. However, this loss was non-differential (difference of a maximum of $4 \%$ ) when comparing the groups of students who knew and did not know the mothers' educational level, considering gender, age group, type of school, score of goods and services (in tertiles) and PA.

Bivariate analysis is described in Table 2 and indicates the factors associated with regular practice of PA, stratified by sex. In the multivariate analysis described in Table 3, a higher prevalence of PA was observed in 14-year-old boys, with brown skin color, children of mothers with some level of schooling, who frequently consumed beans, fruits, vegetables and milk, who did not smoke regularly and had family supervision. On the other hand, there was a lower prevalence of PA in male adolescents who did not work, did not present insomnia, did not consume alcohol regularly and did not try drugs (Table 3). 
Table 2. Factors associated with the regular practice of physical activity of Brazilian adolescents, according to the demographic, psychosocial, behavioral and sociocultural characteristics. Bivariate analysis.

\begin{tabular}{|c|c|c|c|c|c|c|}
\hline \multirow{2}{*}{ Variable } & \multicolumn{3}{|c|}{ Boys } & \multicolumn{3}{|c|}{ Girls } \\
\hline & PR & $95 \% \mathrm{Cl}$ & p & PR & $95 \% \mathrm{Cl}$ & p \\
\hline \multicolumn{7}{|c|}{ Age group } \\
\hline$\geq 16$ & 1 & & & 1 & & \\
\hline 15 & 1.08 & $1.01-1.15$ & 0.019 & 0.93 & $0.83-1.03$ & 0.171 \\
\hline 14 & 1.11 & $1.07-1.16$ & 0.000 & 0.97 & $0.86-1.08$ & 0.537 \\
\hline$\leq 13$ & 1.06 & $0.98-1.14$ & 0.140 & 0.99 & $0.87-1.13$ & 0.870 \\
\hline
\end{tabular}

Skin color

$\begin{array}{lr}\text { White } & 1 \\ \text { Black } & 0.98 \\ \text { Yelow } & 0.97 \\ \text { Brown } & 1.04 \\ \text { Indigenous } & 1.08 \\ \text { Kind of school } & 1 \\ \text { Public } & \end{array}$

Private

0.037

0.649

\section{1}

$0.90-1.06$

0.797

0.92

$0.86-0.99$

0.029

$0.97 \quad 0.80-1.19$

0.251

1.11

$0.99-1.25$

0.072

1.04

$0.97-1.10$

0.94

$0.86-1.03$

0.210

1.08

0.102

1.18

$1.04-1.34$

0.011

Work currently

Yes

No

1

0.85

$0.80-0.89$

$0.70-0.77$

$<0.001$

Mother's schooling

Without schooling

Elementary education (incomplete/complete)

1

Secondary education (incomplete/complete)

1.12

$1.08-1.16$

$<0.001$

1

Higher education (incomplete/complete)

1.19

$1.14-1.24$

$<0.001$

1.02

0.92-1.13

0.742

1.43

$1.34-1.52$

$<0.001$

$1.06-1.21$

$<0.001$

Living with parents

Do not live with parents mother

\section{Only father}

1

Only Mother

0.95

0.86-1.06

0.373

$1.39-1.57$

$<0.001$

Both

0.93

0.83-1.05

0.231

1.09

0.90-1.32

0.375

0.96

$0.86-1.06$

0.397

1.09

$0.96-1.24$

0.167

Feeling of loneliness

Yes

No

1.01

0.95-1.08

0.671

1.01

$0.92-1.12$

0.802

Insomnia

Yes

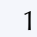

No

0.87

$0.83-0.91$

$<0.001$

0.84

$0.73-0.97$

0.020

Close friends

No

1 friend or more

1

1.08

$1.03-1.13$

0.002

1

Regular consume of beans ( $\geq 5 x /$ week)

No

Yes

$1.20-1.31$

$<0.001$

$1.06-1.23$

$<0.001$

Regular consume of fruits ( $\geq 5 \mathrm{x} /$ week)

No
Yes

egular consume of vegetables ( $\geq 5 x /$ week)

No

1.58

1.52-1.65

$<0.001$

1

Yes

1

1.57

1.52-1.61

$<0.001$

1.92

$1.79-2.06$

$<0.001$

Regular consume of milk ( $\geq 5 x /$ week)

No

1

Yes

1.32

$1.27-1.38$

$<0.001$

1.43

1.36-1.50

$<0.001$ 
Table 2. Factors associated with the regular practice of physical activity of Brazilian adolescents, according to the demographic, psychosocial, behavioral and sociocultural characteristics. Bivariate analysis. (Continuation)

\begin{tabular}{|c|c|c|c|c|c|c|}
\hline \multicolumn{7}{|l|}{ Regular consume of tobacco } \\
\hline Yes & 1 & & & 1 & & \\
\hline No & 0.98 & $0.92-1.05$ & 0.568 & 0.87 & $0.70-1.08$ & 0.212 \\
\hline \multicolumn{7}{|l|}{ Regular consume of alcohol } \\
\hline Yes & 1 & & & 1 & & \\
\hline No & 0.88 & $0.85-0.91$ & $<0.001$ & 0.90 & $0.86-0.95$ & $<0.001$ \\
\hline \multicolumn{7}{|l|}{ Drugs Trying } \\
\hline Yes & 1 & & & 1 & & \\
\hline No & 0.90 & $0.84-0.96$ & 0.001 & 0.80 & $0.71-0.89$ & $<0.001$ \\
\hline \multicolumn{7}{|c|}{ Frequency of meals with parents/guardian } \\
\hline 4 fewer meals per week & 1 & & & 1 & & \\
\hline 5 meals or more per week & 1.08 & $1.01-1.15$ & 0.015 & 1.12 & $1.08-1.15$ & $<0.001$ \\
\hline \multicolumn{7}{|l|}{ Family supervision } \\
\hline No & 1 & & & 1 & & \\
\hline Yes & 1.24 & $1.21-1.28$ & $<0.001$ & 1.26 & $1.16-1.38$ & $<0.001$ \\
\hline \multicolumn{7}{|c|}{ Victim of domestic physical aggression } \\
\hline Yes & 1 & & & 1 & & \\
\hline No & 0.96 & $0.91-1.01$ & 0.103 & 0.85 & $0.78-0.91$ & $<0.001$ \\
\hline \multicolumn{7}{|c|}{ Reaction of parents or guardians if the adolescent arrived drunk } \\
\hline They would care a little & 1 & & & 1 & & \\
\hline They would care so much & 0.97 & $0.89-1.04$ & 0.374 & 0.84 & $0.78-0.90$ & $<0.001$ \\
\hline \multicolumn{7}{|c|}{ Absences at school without parental or guardian permission } \\
\hline Yes & 1 & & & 1 & & \\
\hline No & 1.02 & $0.98-1.07$ & 0.297 & 1.05 & $0.99-1.11$ & 0.086 \\
\hline
\end{tabular}

Numbers with $p$-valor $\leq 0.05$ in bold.

Table 3. Factors associated with the regular practice of physical activity, stratified by sex, according to the demographic, psychosocial, behavioral and sociocultural characteristics.

\begin{tabular}{|c|c|c|c|c|c|c|}
\hline \multirow{2}{*}{ Variable } & \multicolumn{3}{|c|}{ Boys } & \multicolumn{3}{|c|}{ Girls } \\
\hline & PR & $95 \% \mathrm{Cl}$ & $\mathbf{p}$ & PR & $95 \% \mathrm{Cl}$ & p \\
\hline \multicolumn{7}{|l|}{ Age group } \\
\hline$\geq 16$ & 1 & & & & & \\
\hline 15 & 1.02 & $0.96-1.09$ & 0.576 & & & \\
\hline 14 & 1.06 & $1.03-1.10$ & 0.001 & & & \\
\hline$\leq 13$ & 0.99 & $0.94-1.06$ & 0.836 & & & \\
\hline \multicolumn{7}{|l|}{ Skin color } \\
\hline White & 1 & & & 1 & & \\
\hline Black & 0.99 & $0.93-1.07$ & 0.886 & 1.03 & $0.95-1.12$ & 0.456 \\
\hline Yelow & 0.98 & $0.81-1.18$ & 0.801 & 1.19 & $1.06-1.35$ & 0.005 \\
\hline Brown & 1.07 & $1.02-1.13$ & 0.008 & 1.04 & $0.97-1.12$ & 0.268 \\
\hline Indigenous & 1.10 & $0.98-1.24$ & 0.100 & 1.26 & $1.05-1.51$ & 0.011 \\
\hline \multicolumn{7}{|l|}{ Work currently } \\
\hline Yes & 1 & & & 1 & & \\
\hline No & 0.87 & $0.83-0.92$ & $<0.001$ & 0.76 & $0.73-0.79$ & $<0.001$ \\
\hline \multicolumn{7}{|l|}{ Mother's schooling } \\
\hline Without schooling & 1 & & & 1 & & \\
\hline Elementary education (incomplete/complete) & 1.05 & $1.00-1.10$ & 0.041 & 0.96 & $0.86-1.07$ & 0.436 \\
\hline Secondary education (incomplete/complete) & 1.09 & $1.04-1.14$ & $<0.001$ & 1.03 & $0.97-1.09$ & 0.404 \\
\hline Higher education (incomplete/complete) & 1.26 & $1.20-1.31$ & $<0.001$ & 1.27 & $1.19-1.35$ & $<0.001$ \\
\hline
\end{tabular}


Table 3. Factors associated with the regular practice of physical activity, stratified by sex, according to the demographic, psychosocial, behavioral and sociocultural characteristics. (Continuation)

\begin{tabular}{|c|c|c|c|c|c|c|}
\hline \multicolumn{7}{|l|}{ Living with parents } \\
\hline \multicolumn{2}{|l|}{ Do not live with father or mother } & \multicolumn{5}{|c|}{1} \\
\hline \multicolumn{2}{|l|}{ Only father } & & & 1.18 & $0.99-1.41$ & 0.058 \\
\hline \multicolumn{2}{|l|}{ Only Mother } & & & 1.15 & $1.01-1.32$ & 0.035 \\
\hline \multicolumn{2}{|l|}{ Both } & & & 1.07 & $0.96-1.19$ & 0.235 \\
\hline \multicolumn{7}{|l|}{ Insomnia } \\
\hline Yes & 1 & & & 1 & & \\
\hline No & 0.91 & $0.84-1.00$ & 0.044 & 0.89 & $0.80-1.00$ & 0.046 \\
\hline \multicolumn{7}{|l|}{ Regular consume of beans ( $\geq 5 x$ /week) } \\
\hline No & 1 & & & & & \\
\hline Yes & 1.14 & $1.11-1.17$ & $<0.001$ & & & \\
\hline \multicolumn{7}{|l|}{ Regular consume of fruits ( $\geq 5 x /$ week) } \\
\hline No & 1 & & & 1 & & \\
\hline Yes & 1.38 & $1.31-1.44$ & $<0.001$ & 1.63 & $1.52-1.75$ & $<0.001$ \\
\hline \multicolumn{7}{|c|}{ Regular consume of vegetables ( $\geq 5 x /$ week) } \\
\hline No & 1 & & & 1 & & \\
\hline Yes & 1.35 & $1.30-1.40$ & $<0.001$ & 1.39 & $1.31-1.47$ & $<0.001$ \\
\hline \multicolumn{7}{|l|}{ Regular consume of milk ( $\geq 5 \mathrm{x} /$ week) } \\
\hline No & 1 & & & 1 & & \\
\hline Yes & 1.19 & $1.16-1.22$ & $<0.001$ & 1.25 & $1.20-1.30$ & $<0.001$ \\
\hline \multicolumn{7}{|l|}{ Regular consume of tobacco } \\
\hline Yes & 1 & & & & & \\
\hline No & 1.11 & $1.00-1.23$ & 0.050 & & & \\
\hline \multicolumn{7}{|l|}{ Regular consume of alcohol } \\
\hline Yes & 1 & & & 1 & & \\
\hline No & 0.85 & $0.80-0.89$ & $<0.001$ & 0.92 & $0.86-0.98$ & 0.012 \\
\hline Drugs trying & & & & & & \\
\hline Yes & 1 & & & 1 & & \\
\hline No & 0.91 & $0.83-0.99$ & 0.035 & 0.82 & $0.72-0.93$ & 0.002 \\
\hline Frequency of meals with parents/gua & & & & & & \\
\hline 4 fewer meals per week & & & & 1 & & \\
\hline 5 meals or more per week & & & & 1.06 & $1.01-1.10$ & 0.017 \\
\hline Family supervision & & & & & & \\
\hline No & 1 & & & 1 & & \\
\hline Yes & 1.17 & $1.12-1.22$ & $<0.001$ & 1.22 & $1.10-1.34$ & $<0.001$ \\
\hline Victim of domestic physical aggressic & & & & & & \\
\hline Yes & & & & 1 & & \\
\hline No & & & & 0.85 & $0.80-0.91$ & $<0.001$ \\
\hline Reaction of parents or guardians if th & & & & & & \\
\hline They would care a little & & & & 1 & & \\
\hline They would care so much & & & & 0.87 & $0.79-0.97$ & 0.010 \\
\hline
\end{tabular}

Likewise, a higher prevalence of PA was observed in girls with yellow and indigenous skin color, daughters of mothers with higher education, daughters who lived with the mother, frequently consumed fruits, vegetables and milk, had five or more meals per week with parents or guardians and had family supervision. However, a lower prevalence of PA was found in girls who did not work, did not present insomnia, did not consume alcohol regularly, did not try drugs, did not suffer aggression from a relative and whose parents would care a lot if they got drunk at home. It should be noted that the models for boys and girls presented adequate adjustment. 


\section{DISCUSSION}

This is the first Brazilian study, with national representativeness, that found, in adolescents of both sexes, a greater regular practice of PA in teenagers of mothers with higher schooling and under family supervision, showing a possible influence of the family structure in the practice of PA of these youngsters. In addition, PA was positively associated with healthy eating habits such as regular consumption of fruits, vegetables and milk. At the same time, alcohol consumption was prevalent in active adolescents, showing the importance of discussing public policies to prevent this undesirable behavior.

In the present study, it was verified that only $20.2 \%$ of Brazilian adolescents practice PA regularly. Comparing the prevalence of active adolescents in Brazil with those from other countries, it is observed that Brazilians are more active than Ghanaians (16.0\%) and less active than the Argentines and Uruguayans (23.3\% and 27.0\%, respectively) ${ }^{14}$. This low proportion of assets, both in Brazil and in other countries, can be explained partly by the rapid urbanization and the scarcity of public policies to encourage PA, showing the importance of promotion measures to prevent the development of chronic non-communicable diseases in adulthood ${ }^{1,3,15}$.

Age is known as a factor that influences the practice of PA among adolescents, with a tendency of younger age groups to be more active than older ones ${ }^{5}$. A study by Silva et al. ${ }^{16}$ shows that 16 year old adolescents are more absent from Physical Education classes than 15 year old ones, contributing to the greater sedentary lifestyle of the first group. This may be one of the plausible explanations for the greater percentage of assets among 14 year old boys than 16 year old ones. In a stratified analysis (data not shown), we found that 14 year old boys had more physical education classes than 16 year old ones (PR $=1.10$; 95\%CI 1.021.18). The same did not occur among the girls ( $\mathrm{PR}=1.10$, 95\% CI $0.90-1.33)$.

In Brazilian adolescents, the association between PA and skin color has presented inconsistent results ${ }^{7,17}$. While Farias Junior et al. ${ }^{7}$ found no association between the two variables in schoolchildren living in João Pessoa, our study, analyzing adolescents from all over the country, found a higher level of PA in brown skinned boys and in yellow and indigenous skinned adolescents compared with white skinned adolescents. Rezende et al. ${ }^{8}$ had already found association of yellow and brown skin color with active commuting, but their analysis was not stratified by sex. Another study showed that the indigenous population presents a higher level of general $\mathrm{PA}^{18}$. In a stratified analysis (data not shown) using the last tertile of goods and services, a lower socioeconomic level was observed in adolescents with brown (23.0\%), yellow (30.9\%) and indigenous (26.6\%) skin than white ones (37.5\%), which is a possible justification for the higher PA due to active commuting, in view of the lower access to goods and services.

In addition, commuting is probably also responsible for the association between PA and work. Recently, Rezende et al. ${ }^{8}$ found that working adolescents had higher levels of active commuting than those who did not work, probably because the first group belongs to a lower socioeconomic class, who moves to school more often by bicycle or on foot.

The relationship found between higher maternal schooling and regular practice of PA by adolescents can be elucidated by the higher financial level of higher educated families, which would contribute to higher leisure PA due to access to walking and jogging tracks, cycle paths, squares and sport modalities practiced in private places such as clubs ${ }^{5,7}$. Thus, government programs that encourage the increasing of schooling are required, because they may indirectly increase the prevalence of active adolescents.

The presence of the mother or father at home (at the p-value limit of 0.058) was associated with regular practice of PA by girls. The influence of family composition on PA had already been demonstrated in another study9. In a stratified analysis (data not shown), we found a greater leisure PA in girls who lived with mother or father ( $\mathrm{PR}=1.08$; 95\%CI 1.03-1.14) compared to those who do not have parents at home ( $\mathrm{PR}=1.07$; 95\% CI 1.02-1.12). This 
association was not observed among boys, that may be related to the higher determination of this group for the practice of PA in relation to girls ${ }^{19}$, reducing the influence of parents in male adolescents.

The association of insomnia with PA was an unusual result found in our study. Insomnia in adolescents has been attributed to an interaction of intrinsic factors (physical, psychological and social changes) and extrinsic (beginning of schooling) at puberty ${ }^{20}$. In recent literature review, Lang et al..$^{20}$ found that adolescents who do more PA have better sleep quality and therefore less insomnia. Since the PeNSE questionnaire did not evaluate the physical changes and not all the psychological and social variables, this association may have occurred due to the presence of residual confounding factors that remained even after adjustment. It is also emphasized that insomnia was measured by means of a self-reported questionnaire containing only one question about the difficulty of sleeping at night, an important limitation. Another possibility would be the presence of reverse causality, considering that adolescents with insomnia can adopt this practice as a way to reduce $\mathrm{it}^{20-22}$. However, further investigations are required, since this association was maintained in both sexes.

The aggregation of behaviors considered healthy, such as the high level of PA and healthy eating, reported in the present study, has been described in studies evaluating young people. One study found that high levels of PA were associated with regular consumption of vegetables and fruits ${ }^{10}$. In addition, inadequate consumption of fruits, vegetables and greens was associated with low levels of PA in adolescents ${ }^{23}$. Unhealthy habits related to diet and PA and habits considered healthy seem to be concomitant. Then, public policies that invest in increasing of the practice of PA can contribute to the development of healthy eating habits in adolescents.

Regarding the risk behaviors, PA is a protective factor against smoking in male adolescents according this study. Although there are doubts about the relationship between smoking and $\mathrm{PA}^{6}$, our results agree with those of Ali et al. ${ }^{24}$, who also found lower tobacco consumption among active adolescents, probably because smoking reduces the aerobic capacity required for the performance of most sports activities ${ }^{25}$.

Unlike cigarettes, in our study we found a positive association of PA with alcohol consumption and drug trying in both sexes. These results corroborate the study made by Bedendo and $\mathrm{Noto}^{11}$, who also verified greater consumption of alcohol among adolescents attending fitness centers and soccer players in all Brazilian capitals. In another study it was observed that adolescents who participated in sports activities were more likely to abuse alcohol in adulthood ${ }^{25}$. One of the possible explanations is that alcohol consumption can be encouraged among friends who practice PA as a way to strengthen group bonds by facilitating socialization ${ }^{26,27}$. Therefore, it is suggested that public policies aimed at increasing the practice of PA in adolescents should adopt preventive measures to reduce alcohol consumption.

With regard to illicit drugs trying, our result differs from that found by Silva et al. ${ }^{16}$, who did not observe an association of this factor with PA in 6,000 adolescents from the state of Santa Catarina. This divergence can be attributed to the local differences, since the sample of this study is representative of all Brazil. Unlike Silva et al. ${ }^{16}$ and similarly to our results, Horta et al. ${ }^{12}$, when analyzing adolescents from all Brazilian states, found a positive association of illicit substance trying with PA and number of friends. However, it is a matter of trying and not regular use of drugs, this association should be analyzed with caution and more studies are necessary to prove the relationship between these factors.

When analyzing the sociocultural field, more specifically the family context, we found that girls who reported more meals with their parents had a higher chance of being active. Some studies shown that eating more than five meals a week with the family contributes to improving the health and well-being of adolescents ${ }^{28}$. However, it is noteworthy that such association was found only in girls. Possible explanations fall on sex differences related 
to the greater sensitivity and susceptibility of girls in family relationships ${ }^{19,28}$. Recently, Banna et al. ${ }^{29}$ reported that parental guidance influences the choice of healthy foods among adolescents, demonstrating that parent-child dialogue during meals is an incentive for healthy lifestyle habits, possibly including PA.

Another important part of the possible family influence in the practice of PA is represented by the family structure. Berge et al. ${ }^{30}$ demonstrated that boys living in well-structured families have a higher practice of PA, so in our study, boys and girls with family supervision were more likely to be active than the others. This association, coupled with previous ones, shows that government programs that encourage family ties and positive social relationships in this nucleus can contribute to increased practice of PA as well as other healthy habits.

Family aggression and parents who would not care about their children's abusive alcohol consumption were associated with increased regular practice of PA among girls, associations not expected by the authors of the article, since positive family relationships, as described in the previous paragraphs, tend to increase PA practice in adolescents. The explanation may be in the possible residual confounding factors present even after adjusting for several variables.

Among the limitations of the research, it is emphasized that the collection of information through a questionnaire can introduce information bias for most of the variables, including the outcome. Moreover, due to the impossibility of establishing a causal relationship, longitudinal studies for causal inferences are strongly recommended. To the detriment of the limitations, the greatest advantage of this study is its power and sample amplitude, being representative of Brazil.

It was concluded that PA was associated with several demographic, psychosocial, behavioral and sociocultural factors. The positive association of maternal schooling, family supervision and healthy eating habits with the regular practice of PA in boys and girls is particularly noteworthy, which may lead to the elaboration of public policies to promote PA. At the same time, regular alcohol consumption was also associated with PA, highlighting the need to adopt preventive measures to control this behavior.

\section{REFERENCES}

1. World Health Organization. Global status report on noncommunicable diseases 2010. Geneva: WHO; 2011 [cited 2017 Jan 15]. Available from: http://www.who.int/nmh/publications/ncd_ report2010/en/

2. Hallal PC, Andersen LB, Bull FC, Guthold R, Haskell W, Ekelund U, et al. Global physical activity levels: surveillance progress, pitfalls, and prospects. Lancet. 2012;380(9838):247-57. https://doi.org/10.1016/S0140-6736(12)60646-1

3. Instituto Brasileiro de Geografia e Estatística. Pesquisa Nacional de Saúde Escolar 2015. Rio de Janeiro: IBGE; 2016 [cited 2017 Jan 15]. Available from: http://www.ibge.gov.br/home/estatistica/ populacao/pense/2015/default.shtm

4. Instituto Brasileiro de Geografia e Estatística. Pesquisa Nacional de Saúde Escolar 2012. Rio de Janeiro: IBGE; 2013 [cited 2017 Jan 15]. Available from: http://www.ibge.gov.br/home/estatistica/ populacao/pense/2012/

5. Seabra AF, Mendonça DM, Thomis MA, Anjos LA, Maia JA. Determinantes biológicos e sócio-culturais associados à prática de atividade física de adolescentes. Cad Saude Publica. 2008;24(4):721-36. https://doi.org/10.1590/S0102-311X2008000400002

6. Bauman AE, Reis RS, Sallis JF, Wells JC, Loos RJ, Martin BW, et al. Correlates of physical activity: why are some people physically active and others not? Lancet. 2012;380(9838):258-71. https://doi.org/10.1016/S0140-6736(12)60735-1

7. Farias Júnior JC, Lopes AS, Mota J, Hallal PC. Physical activity practice and associated factors in adolescents in Northeastern Brazil. Rev Saude Publica. 2012;46(3):505-15. https://doi.org/10.1590/S0034-89102012005000031 
8. Rezende LF, Azeredo CM, Canella DS, Claro RM, Castro IR, Levy RB, et al. Sociodemographic and behavioral factors associated with physical activity in Brazilian adolescents. BMC Public Health. 2014;14:485. https://doi.org/10.1186/1471-2458-14-485

9. Ramos CGC, Andrade RG, Andrade ACS, Fernandes AP, Costa DAS, Xavier CC, et al. Contexto familiar e atividade física de adolescentes: cotejando diferenças. Rev Bras Epidemiol. 2017;20(3):537-48. https://doi.org/10.1590/1980-5497201700030015

10. Fernandes RA, Christofaro DG, Casonatto J, Kawaguti SS, Ronque ERV, Cardoso JR, et al. Crosssectional association between healthy and unhealthy food habits and leisure physical activity in adolescents. J Pediatr (Rio J). 2011;87(3):252-6. https://doi.org/10.2223/JPED.2093

11. Bedendo A, Noto AR. Sports practices related to alcohol and tobacco use among high school students. Rev Bras Psiquiatr. 2015;37(2):99-105. https://doi.org/10.1590/1516-4446-2014-1389

12. Horta RL, Horta BL, Costa AWN, Prado RR, Oliveira-Campos M, Malta DC. Lifetime use of illicit drugs and associated factors among Brazilian schoolchildren, National Adolescent School-based Health Survey (PeNSE 2012). Rev Bras Epidemiol. 2014;17 Supl 1:31-45. https://doi.org/10.1590/1809-4503201400050004

13. Szwarcwald CL, Souza Júnior-PRB, Esteves MAP, Damacena GN, Viacava F. Socio-demographic determinants of self-rated health in Brazil. Cad Saude Publica. 2005;21 Supl 1:S54-64. https://doi.org/10.1590/S0102-311X2005000700007

14. World Health Organization. Global school-based student health survey (GSHS). Geneva: WHO; 2013 [cited 2017 Jan 15]. Available from: http://www.who.int/chp/gshs/en

15. World Health Organization. Draft comprehensive global monitoring framework and targets for the prevention and control of noncommunicable diseases: Sixty-Sixth World Health Assembly. Geneva: WHO; 2014.

16. Silva KS, Nahas MV, Peres KG, Lopes AS. Fatores associados á atividade física, comportamento sedentário e participação na Educação Física em estudantes do Ensino Médio em Santa Catarina, Brasil. Cad Saude Publica. 2009;25(10):2187-200. https://doi.org/10.1590/S0102-311X2009001000010

17. Santos CM, Wanderley Júnior RS, Barros SSH, Farias Júnior JC, Barros MVG. Prevalência e fatores associados à inatividade física nos deslocamentos para escola em adolescentes. Cad Saude Publica. 2010;26(7):1419-30. https://doi.org/10.1590/S0102-311X2010000700021

18. Santos KM, Tsutsui MLS, Galvão PPO, Mazzucchetti L, Rodrigues D, Agostinho SGA. Grau de atividade física e síndrome metabólica: um estudo transversal com indígenas Khisêdjê do Parque Indígena do Xingu, Brasil. Cad Saude Publica. 2012;28(12):2327-38. https://doi.org/10.1590/S0102-311X2012001400011

19. Wu SY, Pender N, Noureddine S. Gender differences in the psychosocial and cognitive correlates of physical activity among Taiwanese adolescents: a structural equation modeling approach. Int J Behav Med. 2003;10(2):93-105. https://doi.org/10.1207/S15327558IJBM1002_01

20. Lang C, Kalak N, Brand S, Holsboer-Trachsler E, Pühse U, Gerber M. The relationship between physical activity and sleep from mid adolescence to early adulthood. A systematic review of methodological approaches and meta-analysis. Sleep Med Rev. 2016;28:32-45. https://doi.org/10.1016/j.smrv.2015.07.004

21. Countryman AJ, Saab PG, Llabre MM, Penedo FJ, McCalla JR, Schneiderman N. Cardiometabolic risk in adolescents: associations with physical activity, fitness, and sleep. Ann Behav Med. 2013;45(1):121-31. https://doi.org/10.1007/s12160-012-9428-8

22. Dishman RK, Sui X, Church TS, Kline CE, Youngstedt SD, Blair SN. Decline in cardiorespiratory fitness and odds of incident sleep complaints. Med Sci Sports Exerc. 2015;47(5):960-6. https://doi.org/10.1249/MSS.0000000000000506

23. Silva DAS, Silva RJS. Association between physical activity level and consumption of fruit and vegetables among adolescents in northeast Brazil]. Rev Paul Pediatr. 2015;33(2):167-73. https://doi.org/10.1016/j.rpped.2014.09.003

24. Ali MM, Amialchuk A, Heller LR. The influence of physical activity on cigarette smoking among adolescents: evidence from Add Health. Nicotine Tob Res. 2015;17(5):539-45. https://doi.org/10.1093/ntr/ntu171

25. Wichstrøm T, Wichstrøm L. Does sports participation during adolescence prevent later alcohol, tobacco and cannabis use? Addiction. 2009;104(1):138-49. https://doi.org/10.1111/j.1360-0443.2008.02422.x 
26. Korhonen T, Kujala UM, Rose RJ, Kaprio J. Physical activity in adolescence as a predictor of alcohol and illicit drug use in early adulthood: a longitudinal population-based twin study. Twin Res Hum Genet. 2009;12(3):261-8. https://doi.org/10.1375/twin.12.3.261

27. Martens MP, Watson JC, Beck NC. Sport-type differences in alcohol use among intercollegiate athletes. J Appl Sport Psychol. 2006;18(2):136-50. https://doi.org/10.1080/10413200600653758

28. Neumark-Sztainer D, Eisenberg ME, Fulkerson JA, Story M, Larson NI. Family meals and disordered eating in adolescents: longitudinal findings from project EAT. Arch Pediatr Adolesc Med. 2008;162(1):17-22. https://doi.org/10.1001/archpediatrics.2007.9

29. Banna JC, Buchthal OV, Delormier T, Creed-Kanashiro HM, Penny ME. Influences on eating: a qualitative study of adolescents in a periurban area in Lima, Peru. BMC Public Health. 2016;16:40. https://doi.org/10.1186/s12889-016-2724-7

30. Berge JM, Wall M, Larson N, Loth KA, Neumark-Sztainer D. Family functioning: associations with weight status, eating behaviors, and physical activity in adolescents. J Adolesc Health. 2013;52(3):351-7. https://doi.org/10.1016/j.jadohealth.2012.07.006

Funding: Department of Health Surveillance, Brazilian Ministry of Health (Process 23072043160201832 TED 66/2018).

Authors' Contribution: Design and planning of the study: LAC, WTC, DCM. Data collection, analysis and interpretation: LAC, WTC, DCM, OCC, FMS. Writing the manuscript: LAC, WTC, DCM, OCC, FMS. Critical review of the manuscript: LAC, WTC, DCM, OCC, FMS. Public responsibility for the content of the article: LAC, WTC, DCM, OCC, FMS.

Conflict of Interest: The authors declare no conflict of interest. 